\title{
ESPIRAL PÓS-MODERNA
}

\author{
Michel Maffesoli ${ }^{1}$
}

O fim do mundo não é o fim do mundo. Mas a agonia da modernidade nos incita a pensar o que virá sucedê-la. O que alguns, e inclusive eu, chamam a « pós-modernidade », na falta de nome melhor. Sim, estou falando da «pós» modernidade, e não do que o conformismo lógico-intelectual qualifica de: segunda modernidade, hipermodernidade, modernidade tardia e outras loucuras do mesmo tipo. A casa está queimando, e queremos salvar os móveis! Por conta disso, algumas banalidades básicas devem ser relembradas :

- a história mostra repetidamente que todo desmoronamento pode ser o gatilho de uma Renascença.

- para isso, nós devemos transformar uma fraqueza em uma virtude ; e isso no sentido forte, ou seja, em uma força.

- estando claro que é necessário, desde já, encontrar as palavras menos falsas possíveis ; pois, como se sabe : «nomear mal as coisas contribui com a miséria do mundo »!

O que dizer então dessa pós-modernidade? Rapidamente, à prevalência dos grandes valores ocidentais sucede o que eu chamei de « orientalização do mundo ». São esses « orientes míticos » que precisamos, ao mesmo tempo, identificar e analisar.

É, certamente, sempre arriscado «remexer» as marmitas do futuro. Podemos, no entanto, dar algumas indicações, juntar algumas pistas, com o objetivo de indicar grandes tendências. Ainda mais já que vemos a volta, ligeiramente modificada, do que pensávamos estar ultrapassado. Para ser mais preciso, não se trata de um « eterno retorno » do mesmo, mas, como indicava em seu tempo o filósofo Nicolas de Cusa, de um crescimento cuja

\footnotetext{
${ }^{1}$ Professor Emérito da Université de Sorbonne, França. É doutor em Sociología e Letras e Ciências Humanas e discípulo de G. Durand. Tem diversas premiações acadêmicas, entre elas é Doutor Honoris Causa pelas Universidades de Bucareste (Romênia), Braga (Portugal), PUC Porto Alegre (Brasil) e Universidade Autônoma do Estado do México (Toluca de Lerdo, México).
} 
paisagem toma a forma da espiral. Para dizê-lo de forma ainda mais clara, se devêssemos definir, provisoriamente, a pós-modernidade, poderíamos definí-la como : «a sinergia de fenômenos arcaicos e do desenvolvimento tecnológico ».

É assim que, para retomar os grandes temas explicativos da modernidade : Estado nação, instituição, sistema ideológico, podemos constatar, no que diz respeito à pósmodernidade, a volta do local, a importância da tribo e a gambiarra mitológica.

Primeiramente, o local. Primeiro índice da heterogeneização galopante que percorre nossas sociedades. É interessante, quanto a isso, notar o retorno em força, nos diversos discursos sociais, de termos como o de "país », « território », « espaço », que se referem todos a um sentimento de pertencimento reforçado, à troca emocional. Ou seja, ao fato de que o local cria laços. Um laço que não é abstrato, teórico, racional. Um laço que não se constituiu a partir de um ideal longínquo, mas, pelo contrário, que se fundamenta, organicamente, na possessão comum de valores enraizados: língua, costumes, cozinha, posturas corporais. Todas coisas cotidianas, concretas, que aliam em um paradoxo mais do que aparente o material e o espiritual de um povo. Deve-se refletir sobre o assunto: tal materialismo espiritual, vivido localmente, é o que vai, cada vez mais, substituir o político em suas diversas modulações.

Enraizamento dinâmico como causa e efeito da fragmentação institucional. De fato, as diversas instituições sociais, que se tornaram cada vez mais abstratas e desencarnadas, não parecem mais à altura da exigência reafirmada de proximidade. Daí a emergência de um neotribalismo pós-moderno que repousa sobre a necessidade de solidaridade e de proteção que caracteriza todo o conjunto social. Nas selvas de pedra que são as megalópoles contemporâneas, a tribo assume o papel que era seu na selva stricto sensu.

Assim, é incrível constatar que as diversas instituições não são mais contestadas ou defendidas. Elas estão simplesmente «corroídas» e servem de leito a microentidades fundadas na escolha e na afinidade. Afinidades eletivas que encontramos no seio dos partidos, das universidades, sindicatos e outras organizações formais, e que funcionam segundo as regras da solidariedade de uma franco-maçonaria generalizada. Isso ocorre, é claro, para o melhor e para o pior. Tribos religiosas, sexuais, culturais, esportivas, musicais, seu número é infinito, sua estrutura é idêntica : entreajuda, compartilhamento de sentimentos, atmosfera afetuosa. E podemos supôr que tal fragmentação da vida social venha a se desenvolver de forma exponencial, constituindo assim uma nebulosa intangível sem centro preciso nem 
periferias dicerníveis. O que resulta em uma socialidade fundada na concatenação de marginalidades das quais nenhuma é mais importante que a outra.

É uma dessas estruturas sociais que induz o que podemos chamar de gambiarra mitológica. Talvez seja pouco oportuno falar do fim das ideologias. No entanto, é possível constatar sua transfiguração. Elas tomam outro rosto. $\mathrm{O}$ das pequenas narrações específicas, próprias, é claro, à tribo que as detém. As «grandes narrações de referência » se particularizam, se encarnam, se limitam à dimensão de um território específico. Daí as práticas linguajares juvenis, a volta dos dialetos locais, o recrudescimento dos diversos sincretismos filósofos ou religiosos.

A verdade absoluta, que deve ser atingida, se fragmenta em verdades parciais que convêm ser vividas. O que desenha bem os contornos da estrutura mitológica. Cada território, real ou simbólico, secreta de alguma forma seu modo de representação e sua prática linguajar: «Cujus regio cujus religio ». Daí a babelização potencial que trabalhamos, comumente, a negar ao invocar o espectro da globalização. Na verdade, há várias uniformizações mundiais : econômicas, musicais, de consumo, mas devemos nos perguntar sobre sua verdadeira pregnância. E nos perguntar se a verdadeira eficácia não deve ser procurada do lado dos mitos tribais e de seu aspecto existencial. A comunicação em redes, da qual a Internet dá uma boa ilustração, forçaria assim a repensar, nesse sentido, para a pósmodernidade, o « universal concreto » da filosofia hegeliana.

Se estamos de acordo, hipoteticamente, sobre um local tribal que genera pequenas mitologias, qual poderia ser seu substrato epistemológico ? Empiricamente, parece que o Indivíduo, a história e a Razão dão pouco a pouco espaço à fusão afetuosa que se encarna no presente nas imagens comunais.

O termo de indivíduo, eu já disse, não parece mais caber. Ou pelo menos não em seu sentido restrito. Talvez devêssemos falar, no que diz respeito à pós-modernidade, de uma pessoa («persona ») que assume papéis diversos no seio das tribos das quais faz parte. A identidade se fragiliza. As identificações múltiplas, no entanto, se multiplicam.

Os grandes encontros musicais, esportivos, e de consumo são testemunha disso. Em cada um desses casos, se trata de se perder no outro. «Despesa », no sentido de G. Bataille, como busca da fusão. Cada um existe apenas dentro e pelo olhar do outro. E isso funciona, que o outro seja o da tribo de afinidade, que seja a alteridade da natureza, ou ainda o grande Outro que é a deidade. Fusões, confusões de diversas ordens que não deixam de lembrar o 
mito dionisíaco. Se trata aqui de um processo que é nada menos que excepcional, mas que remete, pelo contrário, à simples realidade cotidiana. Vários são os fenômenos da vida do dia a dia que são, sem esse processo, incompreensíveis. Em todas as disciplinas o «tornar-se moda» do mundo está em voga. E as «leis da imitação », propostas, de forma « intempestiva », por Gabriel Tarde parecem ser a regra atual.

Em outras palavras, não é mais a autonomia : eu sou a minha própria lei que prevalece, mas a heteronomia: minha lei é o outro.

Talvez seja essa a mudança paradigmática mais importante. Ela ocorre junto com a inversão do tempo que faz com que a história linear tenha menos importância que as histórias humanas. «Einsteinização» do tempo, como já foi dito. Ou seja, o tempo se contrai em espaço. Ou seja, o que vai predominar é um presente que eu vivo com outros em um dado local. Qualquer que seja a forma de nomeá-lo, um tal presenteismo vai contaminar as representações e as práticas sociais, principalmente juvenis. É um «carpe diem », vindo de memória antiga, que traduz um hedonismo difuso. O gozo não é mais atribuído a hipotéticos « amanhãs que cantam », ele não é mais esperado em um paraíso que está por vir, mas ele é vivido, bem ou mal, no presente.

Nesse sentido, o presente pós-moderno se junta à filosofia do « kairos » que focou nas ocasiões e nas boas oportunidades. A existência não passa, de certa forma, de uma progressão de instantes eternos que devem ser vividos, da melhor forma possível, aqui e agora. Talvez tenhamos que lembrar, aqui, uma distinção importante. A do drama e do trágico. Quanto mais o drama, em seu sentido etimológico, evolui, tende a uma solução possível, coisas que encontramos no «burguesismo » moderno, mais o trágico é « afórico », ou seja, não busca, não espera soluções, resoluções. Podemos até mesmo dizer que ele repousa sobre a tensão dos elementos heterogêneos.

O último ponto, finalmente, do substrato epistemológico pós-moderno, é a importância que vai tomar a imagem na constituição do sujeito e na constituição da sociedade. Aqui, novamente, devemos ser alusivos, e remeter às análises que abordaram como tal esse problema. Basta lembrar que, no embalo da tradição judaico-cristã, a modernidade foi, essencialmente, iconoclasta. Assim como, na tradição bíblica, o ícone ou o ídolo não permitia a adoração do verdadeiro Deus, « em espírito e em verdade », a imagem ou o imaginário, de Descartes a Sartre, tornava-se obstáculo ao bom funcionamento da razão. Lembremos aqui a expressão filosófica, que se tornou provérbio popular e que faz da imaginação a «louca da 
casa ». Essa é uma estigmatização que marcou, profundamente, nossos modos de pensar e toda a nossa sensibilidade teórica.

Mas o que observamos hoje, senão o retorno em força dessa imagem negada e renegada? Imagem publicitária, imagem televisual, imagem virtual. Nada se salva. « Imagem de marca » intelectual, religiosa, política, industrial etc., todos e todas as coisas devem se dar a ver, fazer-se espetáculo. Podemos dizer, numa ótica weberiana, que podemos compreender o real a partir do irreal (ou do que tem tal reputação). Acontece que, durante a modernidade, o desenvolvimento tecnológico havia, duravelmente, desencantado o mundo. Podemos dizer que, no que diz respeito à pós-modernidade nascente, é a tecnologia que favorece um real reencantamento do mundo.

Afim de acentuar tal fenômeno, podemos falar do (re)nascimento de um « mundo imaginal ». Ou seja, de uma forma de ser e de pensar atravessada, inteiramente, pela imagem, o imaginário, o simbólico, o imaterial.

Qualquer que seja a forma desse « imaginal» de se exprimir : virtual, lúdico, onírico, ele estará aqui, presente e pregnante, ele não será mais prisioneiro da vida privada e individual, mas será o elemento constitutivo de um estar-juntos fundamental. É tudo isso que pode nos levar a dizer que o social se torna socialidade ao integrar, de forma « holística », os parâmetros humanos que o racionalismo moderno havia deixado de lado. O imaginal é, assim, uma outra forma de atrair a atenção para a sociedade complexa, a solidariedade orgânica que está se preparando, para a «correspondência", no sentido de Baudelaire, entre todos os elementos do ambiente social e natural.

Nossa época é, talvez, mais atenta à impermanência das coisas mais estabelecidas. O que é certo, é que a emergência de valores arcaicos que pensávamos estar totalmente ultrapassados deve tornar-nos atentos ao fato que, se as civilizações são mortais, a vida, curiosamente, perdura. Assim, sem atribuir a esse termo um estatuto conceitual demasiado rígido, a pós-modernidade nascente nos relembra que a modernidade foi uma "pósmedievalidade », ou seja que ela permitiu uma nova composição do estar-juntos.

O vir-a-ser espiralesco do mundo! Quando desfalece a evidência de uma ideia sobre a qual se fundava uma dada civilização, uma outra constelação nasce, integrando certos elementos do que foi, e devolvendo vida a alguns outros que haviam sido renegados.

É levando em conta esse esquema que podemos, de uma forma não judicativa, não normativa, epifanizar as grandes características da episteme pós-moderna. O que M. Foucault 
já fez para a modernidade deve ser feito para uma época que se anuncia. Trata-se de um grande desafio que necessita uma postura intelectual audaciosa. Desafio que deve ser levado em conta, se não quisermos que o pensamento seja marginalizado. Ainda mais sabendo que, como dizia Victor Hugo em uma outra época, « nada para uma ideia cujo tempo chegou ».

\section{REFERÊNCIAS BIBLIOGRÁFICAS}

DURAND, G., Les Structures anthropologiques de l'imaginaire, Bordas, 1960. . Beaux arts et archétypes, PUF, 1986.

MAFFESOLI, M...L'Ombre de Dionysos (1982), trad. A Sombra do Dionisio. Rio. 1985. Le Temps des tribus (1988), trad. O tempo das tribos. Rio. Forense. 3a ed. 2000. . L'ordre des choses. CNRS Éditions. 2014. . Le Trésor caché, lettre ouverte aux Francs-Maçons. Ed Leo Scheer. 2015.

MORIN, E., Pour entrer dans le XXIe siècle.

MOSCOVICI, S., La Machine à faire les dieux, fayard, 1990. 